\title{
UNIVERSAL DESIGN FOR LEARNING: ASSESSMENT OF TEACHING METHODS IN COVENANT UNIVERSITY, OTA, OGUN STATE, NIGERIA
}

\author{
A. Sholanke, A. Adeboye, O. Alagbe, U. Ugah \\ Department of Architecture, Covenant University (NIGERIA)
}

\begin{abstract}
Universal Design for Learning (UDL) is another perspective about educational training. It is regarded as an essential implement in the pre-emptive planning of manageable and usable all inclusive learning and teaching methods, and environments. Classroom use of UDL includes the utilization of innovation and different methods of instruction among others as captured in its three core principles of representation, expression and engagement. The purpose of this investigation is to assess the compliance of the various teaching methods employed in Covenant University (CU) in Ota, Ogun State, Nigeria, with the UDL principles, with a view to identifying possible areas for improvements. CU is a private university whose goal is to be one of the best ten universities in the world by 2022 . Thus the need to have its teaching methods conforms to international best practices. The study employed a qualitative research approach using structured interview specifically designed for the research to collect data. The analyzed data is presented using descriptive approach. The outcome of the study will be useful to guiding policies towards achieving inclusive education in higher institution of learning, particularly in Nigeria and other developing nations.
\end{abstract}

Keywords: Universal Design for Learning, Teaching Methods, Technology.

\section{INTRODUCTION}

The right to education as recognized by a number of international conventions, including article 13 of the United Nations 1966 International Covenant on Economic, Social and Cultural Rights (ICECR) [1] incorporates among others obligations to avoid discrimination at all levels of the educational system. This discrimination has been attributed to be the outcome of the oversimplification of the classification of learners into "smart and not smart", "disabled and not disabled", and "regular and not regular" in the application of traditional teaching methods [2]. However, these teaching methods are found to be inadequate in ensuring that the ideals as captured by Article 13 of the ICECR and other relevant laws are fulfilled (3).

Attempts to remedy these anomalies has led to the development of various concepts aimed at providing equal opportunities for every individual to acquire formal education, regardless of their ability or inability (3). Notably among these concepts is Universal Design for Learning (UDL), a concept motivated by the Universal Design (UD) crusade in architecture and product development, which directs the advancement of adaptable learning condition to meet the various learning styles which results from individual differences (4).

The UD concept started from the field of architecture because of the need to ensure access to physical structures for people with disabilities (PWD). In 1997, a gathering of professionals comprising of architects, designers, and engineers came up with the seven principles of UD which have had so much influence on the design of products, environments and communication. These guiding principles are: equitable use; flexibility in use; simple and intuitive use; perceptible information; tolerance for error; low physical space; and size and space for approach and use (5).

UD centres on removing physical and virtual boundaries through innovative and original designs at conception that consider the requirement of diverse individuals, rather than removing these boundaries using singular adjustments or adaptations. Since the targeted groups are whole communities, UD environments are built for adaptability and designed in ways anticipating the need for multiple choice, alternatives and adjustments, to address the need for varieties. Subsequently, plans are regularly flexible and variable as opposed to being devoted to a typical user. They are not one of a kind or tailored to an individual, but rather comprehensive and all inclusive. UD is an ideal that is not yet met totally in reality (6) 
UD has been applied in many fields such as architecture, product design, urban design, information and technology. Its application is can also be seen in education. UD for education is an approach to ensure that educational programmes can serve all learners (7) including those with disabilities. One of the areas where UD has been applied in education is UDL.

UDL is another perspective on education training, which can possibly change the way educational modules are designed and make learning experience more open and significant for all learners (25). These learning experiences are hinged on researches carried out by the Centre for Applied Special Technology (CAST) which refer to 3 sets of brain networks when taken together explain how the brain functions while learning. These networks include recognition, strategic and affective networks, further explained as the "what", "how", and "why" of learning (2).

UDL is a part in the general development toward UD. The term highlights the exceptional importance of learning conditions. They are not made just as a shelter that contains equipment's used for to transmit information, but are made to help and encourage the adaptations in knowledge and skills that we call learning. While giving access to information or to materials is essential to learning, it is often inadequate. UDL requires that we not only ensure we have accessible information, but also ensure accessible teaching methods. In general terms, instructional teaching method is the art of educating and learning. They are the instructive techniques that trained teachers use to feature basic highlight, stress big ideas, elucidate fundamental connections, give graduated platforms to rehearse and practice, display master execution to guide and coach the students. These and more are what instructing and teaching is and the measure of their success is what is referred to as learning (6).

CAST and the National Centre to Improve the Tools of Educators (NCITE), guided by the concept that has started in architecture, developed the needed structure for UDL (4) as shown in Table 1.

Table 1. Principles and Guidelines of Universal Design for Learning

\section{Principles and Guidelines \\ Principle I: Provide Multiple Means of Representation \\ Guideline 1: Provide options for perception \\ Guideline 2: Provide options for language, mathematical expressions, or symbols \\ Guideline 3: Provide options for comprehension \\ Principle II: Provide Multiple Means of Action and Expression}

Guideline 4: Provide options for physical action

Guideline 5: Provide options for expression and communication

Guideline 6: Provide options for executive functions

Principle III: Provide Multiple Means of Engagement

Guideline 7: Provide options for recruiting interest

Guideline 8: Provide options for sustaining effort and persistence

Guideline 9: Provide options for self-regulation

\section{Descriptors}

Provide content and materials in a variety of formats, including physical, symbolic, and linguistic examples. Offer content and materials in multiple, flexible formats (audio, visual, tactile).

Clarify language, mathematical expressions, or symbols and scaffold understanding with alternative or multiple representations.

Build on or supply background knowledge, emphasize important ideas, and support cognitive and metacognitive strategies.

Provide multiple and varied opportunities for students to demonstrate their knowledge and skills.

Use varied and alternative ways for students to physically interact with instructional materials or complete instructional tasks.

Offer multiple media, tools, opportunities, and formats for students to demonstrate their knowledge and understanding of a subject.

Support students' goal setting, planning, information and resource management, and progress monitoring.

Provide students with multiple and varied opportunities to develop and sustain interest in a topic, as well as monitor their skill and knowledge development.

Present relevant learning activities with authentic opportunities for students to make choices, while reducing threats and negative distractions.

Build in reminders, vary the level of task demand, and foster collaboration among students.

Foster self-reflection present opportunities for students to monitor their knowledge and skill development. 
The three segments of the structure are: various methods for depiction (giving substance in various manners, for example, visual, realistic, sound-related, so all learners have various approaches to get information); numerous methods for articulation (giving understudies numerous chances to show what they have being thought); and different methods for engagement (giving an assortment of approaches to include students in learning (8). The principles are useful for guiding and influencing the design process, influence and acknowledge the signalling of more usable products and environments [9]

Smith (2012) posited that UDL can enhance learning experience for all students due to its capacity to provide the said framework for an instructor to expand opportunities in the delivery of course instruction. UDL can also improve educational outcomes for a range of learners by considering its principles in the design of instructional goals, methods, classroom materials and assessments [10] and [11].

UDL guidelines are about ensuring there are sufficient choices, adaptability and options are incorporated with the educational curriculum. The objective is to provide challenges for the most gifted learner, while giving an assortment of alternatives and platforms for the most struggling learners. It enables learners to express their newly found knowledge in numerous ways and make a positive experience in learning, which is advantageous to the learners, family and school (12).

[13] rightly noted that UDL does not conflict with other methods and practice but it actually supports many current research based approaches to teaching and learning. These approaches include cooperative learning (group work), differential guideline, execution based appraisals, venture based learning, multi-tangible learning, hypothesis of numerous knowledge and standards of student focused learning.

The review of some studies on the development of UDL indicates that it benefits all learners particularly those with learning difficulties [4] [14] and [15]. Little wonder, the concept is being adopted by many institutions of learning as a road map to getting educational programmes to every student in line with international best practice of inclusive education.

\section{TEACHING METHODS}

Teaching is defined as the art of arousing curiosity of a matter in a person and also improving the skills needed to ensure that knowledge is gained from that curiosity [16]. Teaching methods largely include: lectures, individual presentation, assignments, seminars, group discussion, workshops, conferences, brainstorming, role pay and case studies [17]. [18] classified teaching methods under two main categories namely: lecturing (to go on) and facilitation (a dynamic process). [19] in his book titled 'What teachers need to know about teaching methods' examined different concepts of teaching methods, which are majorly grouped as either constructivism or instructivism, further referred to as learner-centred and teacher focused approaches respectively, by Prosser and Trigwell (2006) as cited by [19]. [20] suggested a third method he called teacher-learner interactive approach. This is a combination of the teacher and learner focused approaches which merges the attributes of both approaches. This method is more preferable as it allows for appropriate and prompt feedback that benefits both the teacher and learners.

Covenant University (CU) in Ota, Ogun State, Nigeria is a 16-year-old private university in Nigeria. The University is already being ranked high in some research areas among world universities and rated among the top 10 in others, based a recent survey released by Elsevier Scival [21]. The University's goal is to be among one of the top ten universities in the world by the year 2022. To achieve this goal it is important that the university's teaching and learning methods conform to international best practice, easily providing multiple means of representative action, expression and engagement while improving education outcomes for every student, especially those with learning disabilities.

The aim of this study therefore is to investigate the compliance of the CU's teaching methods with the UDL principle with a view to ascertain the level of the institutions preparedness in aligning with its goal of being one of the best universities in the world in the nearest future. The school of postgraduate studies of the university can be regarded as the "engine room" for research and development in the institution. Hence the scope of the study is limited to teaching methods employed by the post graduate lecturers. 


\section{METHODOLOGY}

The study adopted a qualitative research approach. The number of postgraduate programs in CU currently stands at 41 spread across 6 colleges. 5 postgraduate lecturers were randomly selected from each of the colleges and interviewed to find out the teaching methods employed in their various programs and how they are applied. Their responses were transcribed, coded and analyzed according to themes to make them easy to examine their compliance with UDL principles. The study was conducted between 15th of November 2017 to January 8th 2018.

\section{RESULTS}

The main teaching methods employed in $\mathrm{CU}$ to teach postgraduate students are found to be lecturing, seminars and assignments.

\subsection{Lecturing}

$\mathrm{CU}$ lecturers mostly use electronic boards to display digital text, pictures, illustrations and videos to teach the students about any particular subject at the postgraduate level. White boards that lecturers can used coloured markers as a writing or illustration material on, are used as backups to the electronic boards. In addition to presenting lecture materials in class, they are also uploaded on the internet using a module platform accessible to all students. The lecturers also employ the use of interactive sessions, using questions and answers technique during lectures as a way of assessing how far the students are understanding the topic been taught. Tutorial sessions are also organised for the students to tackle problems by interacting and sharing ideas among themselves. In large classes, public address systems are employed to ensure that the lecturers are loud enough to be heard clearly by all present. In CU, every postgraduate course is usually taught by two or more lecturers. The lecture method is a teacher focused method as earlier identified by [19]. This method gives quick exposure to new materials, allows the lecturer to have greater control in the classroom, and facilitates large class communication among others, as noted by [17]. The lecturing method is the mostly used teaching approach by lecturers in the university according to about $70 \%$ of the respondents.

\subsection{Seminar}

Seminar presentation in $\mathrm{CU}$, like most institutions, is a form of academic instruction teaching method used to inform students on particular subjects or topics. The postgraduate students are usually given a research topic or allowed to come up with one within the scope of their curriculum. As the students' progress with their research work, they discuss their ideas and findings with their lecturers or assigned supervisors from time to time for guidance. This makes the seminar teaching method employed in $\mathrm{CU}$ a teacher-learner interactive approach, with the supervisor's role being limited to that of an adviser that gives direction to the student. This allows the students more control and freedom to come up with innovative ideas. According to [22] the seminar is generally a place where assigned readings are discussed, questions raised and debates can be conducted. The seminar teaching method gives the students the opportunity to present their work to a larger audience, thereby providing the students with the opportunity to be active in learning, as noted by [17]. At the end of their research, each student presents his or her findings in a seminar to the lecturers with other students in attendance or to a group of examiners with or without other students in attendance, for grading. The students present their work methodically with the aid of electronic boards in power point presentation format. Microphones and speakers are often used to amplify the students' voice, particularly in large halls, so they can be heard by all present. In addition to the seminar presentation, the students also submit bind hard copies of their research work in A4 format and electronic soft copies. These submissions are eventually deposited in the school's library and digital repository as a reference material for other researchers to use.

\subsection{Assignments}

In CU, assignments are used to increase students' knowledge and improve their abilities and skills as acknowledged by [23]. The assignments are also used to prepare students for upcoming lessons, to extend what they know by having them apply it to new situations, or to integrate their abilities by applying different skills to a single task. It is generally used in $\mathrm{CU}$ to reinforce what the students have already being taught as stated by [24]. The assignments are usually submitted in bind hard copies in A4 or A3 format depending on the content of the submissions. A date is generally fixed for the 
submission of an assignment. After an assignment is submitted, it is corrected and graded, after which scripts are returned to the students. The returned scripts thereafter become a resource/reference material for the students to use in the course of their studies.

Haven identified the teaching methods employed in line with the aim of the study, their compliance level to the three principles of UDL are hereby presented as follows:

\subsection{Principle 1: Providing multiple means of representation}

As students differ in how they understand information, the three methods of teaching used in CU allow the lecturers several means of presenting their lectures to meet the needs of a variety of students with diverse abilities. The use of electronic boards allows the lecturers to present their lecture notes in large, legible and clear digital presentations using a variety of means, such as text, pictures, objects, photos and videos. Upload of lecture materials on a module platform, also affords students the opportunity of having their lecturers' presentations handy as a reference and study material anytime. Lecture materials uploaded on the module platform also affords students who did not attend a class to still have the lecture material to use. It is however observed that the use of braille and sign language does not exist as a means of teaching the post graduate students in the institution. This makes lecture delivery at post graduate level, to some extent, inaccessible to the visually and hearing impaired students. Nevertheless, the teaching delivery methods used at the postgraduate level in CU can be said to be reasonably compliant with providing multiple means of representation in line with the requirement of the first principle of UDL.

\subsection{Principle 2: Providing multiple means of action and expressions}

Students differ in how they navigate a learning environment to express what they know. The use of seminars and assignments for after class assessment of student's knowledge of a topic, as well as the use of questions and answers technique during the teaching of a subject, allow students to have multiple options to present their ideas to lecturers and fellow students. Students who have stage fright for instance, get the opportunity to also present their work in bind hard copies and soft copies. In addition, these methods also provide the lecturers with several options to use in teaching the students, as demanded by the requirements of the second principle of UDL. The use of two or more lecturers to teach a course also allows for multiple means of expression from the lecture delivery angle. The study findings however revealed that it is usually the lecturers or the requirement of a course that dictates what method is to be used to teach a course. Where it is the course content that dictates the teaching method to be used in teaching a particular course, the lecturers cannot use other methods. They can only use the different techniques limited to the method recommended for teaching of the course. This will not allow lecturers to meet the needs of all categories of students' contrary to the requirements of the second principle of UDL. Nonetheless, the teaching delivery methods used at the postgraduate level in CU are also considered reasonably compliant with providing multiple means of action and expression as the second principle of UDL demands.

\subsection{Principle 3: Provide multiple means of engagement}

Generally, students differ in the ways they are motivated to learn. While some students can be selfmotivating and quick to learn in a formal setting, others get motivated and learn better in a less formal interactive class, where all sorts of informal techniques such as feedbacks on personal experiences, storytelling and jokes are used as a way of getting what is being taught to sink better in the students. Some students also learn better when given the opportunity to express themselves in seminars (oral presentation) or assignments (written presentation). The use of seminars and assignments also tend to generally sustain students' curiosity level and help to determine to what extent they can dig more to understand a topic, after lecture hours. Generally, all the three methods employed to teach postgraduate students are considered reasonably adequate to allow multiple means of engagement, hence can be said to be compliant to a large extent with the third principle of UDL.

\subsection{Limitations}

This study has some limitations, one of which is the small sample size used. It is possible that if more lecturers where included as respondents, it could lead to the discovery of more teaching methods not mentioned. Another limitation is that the result gives a picture of the teaching methods used generally at the post graduate level in the university. This might not be a fair representation of what obtains in every course, as some lecturers were found to be using only a method to teach courses assigned to 
them. More studies are therefore encouraged in this regard to find out the position of the compliance of the teaching methods employed for each course or by each lecturer.

\section{CONCLUSIONS}

The study is an investigation to determine the teaching methods used at the postgraduate level in CU and how they comply with the requirements of the three principles of UDL. The study identified lecturing, seminars and the use of assignments as the three main methods employed to teach postgraduate students in the university. The methods and the various techniques employed by the lecturers to teach the students are generally, to a large extent found to be reasonably complaint with all the three principles of UDL. Nonetheless, some areas were found wanting. Based on the findings the following conclusions are made. Firstly, the use of braille and sign language found to be lacking, should be introduced as a starting point to making the teaching methods comply fully with the principle of UDL. This will enable the university meet the peculiar needs of every student, particularly those with severe visual and hearing impairments, in accordance with the dictates of inclusive education. It will also help to ensure that the university curriculum is accessible to all categories of students no matter their level of ability or disability, in line with international best practice. Secondly, the university's lecturers generally should be adequately trained to understand and appreciate the principles of UDL and how to apply them to benefit all students at all levels. And lastly, lecturers should also be encouraged to use different techniques to teach the same course, rather than relying only the method specified by the requirement of a curriculum, which might not fully comply with all the requirements of the three principles of UDL. Usually, it is the use of a combination of different teaching methods that leads to complying with all the three UDL principles.

\section{ACKNOWLEDGEMENTS}

This is to recognise the management of Covenant University, Ota, Ogun State, Nigeria for being the sole sponsor of this conference paper. Thank you.

\section{REFERENCES}

[1] Assembly, UN General. "International covenant on economic, social and cultural rights." United Nations, Treaty Series 993, no. 3, 1966.

[2] T.E. Hall, A. Meyer, D. H. Rose, (Eds) "Universal design for learning in the classroom: Practical applications". Guilford Press; 2012.

[3] T. Hehir, "Policy foundations of universal design for learning." A policy reader in universal design for learning 35-45., 2009.

[4] D. H. Rose, A. Meyer, "Teaching every student in the digital age: Universal design for learning." Association for Supervision and Curriculum Development, 1703 N. Beauregard St., Alexandria, VA, 22311-1714 2002

[5] The Center for Universal Design, "The Principles of Universal Design, Version 2.0." Raleigh,NC: North Carolina State University 1997.

[6] D. H. Rose, W. S. Harbour, C. S. Johnston, S. G. Daley, and L. Abarbanell. "Universal design for learning in postsecondary education: Reflections on principles and their application." Journal of postsecondary education and disability Vol. 19, no. 2, 135-151., 2006.

[7] S. Burgstahler, Preface. In S. Burgstahler (Ed.). Universal design in higher education: Promising practices. Seattle: DO-IT, University of Washington. 2015. Retrieved from www.uw.edu/doit/UDHE-promisingpractices/preface.html

[8] R. Orkwis, and K. McLane. "A Curriculum Every Student Can Use: Design Principles for Student Access. ERIC/OSEP Topical Brief." 1998.

[9] A. B. Sholanke, A. B. Adeboye, A. A. Oluwatayo, and O. A. Alagbe. "Evaluation of Universal Design Compliance at the Main Entrance of Selected Public Buildings in Covenant University, Ota, Ogun State, Nigeria.", 188-192, 2016. 
[10] C. Hitchcock, and S. Stahl. "Assistive technology, universal design, universal design for learning: Improved learning opportunities." Journal of Special Education Technology Vol. 18, no. 4, 45-52, 2003.

[11] D. H. Rose, and N. Strangman. "Universal design for learning: Meeting the challenge of individual learning differences through a neurocognitive perspective." Universal Access in the Information Society Vol. 5, no. 4, 381-391, 2007

[12] C. L. Schelly, P. L. Davies, and C. L. Spooner. "Student perceptions of faculty implementation of Universal Design for Learning." Journal of Postsecondary Education and Disability Vol. 24, no. 1, 17-30, 2011.

[13] M. Grace. "Curriculum planning for all learners: Applying universal design for learning (UDL) to a high school reading comprehension program." Preventing School Failure: Alternative Education for Children and Youth Vol. 52, no. 2, 21-30, 2008.

[14] B. Pisha, and P. Coyne. "Smart from the start: The promise of universal design for learning." Remedial and special education Vol. 22, no. 4, 197-203, 2001.

[15] A. G. Dell, D. A. Newton, and J. G. Petroff. "Assistive technology in the classroom: Enhancing the school experiences of students with disabilities." Pearson, 2016.

[16] M. M. Duruji, D. E. Azuh, S. Joshua, I. P. Olanrewaju, and U. Okorie. "Teaching Method and Assimilation of Students in Tertiary Institutions: A Study of Covenant University, Nigeria." 51165126, 2014.

[17] S. Sajjad, "Effective teaching methods at higher education level." Pakistan Journal of Special Education Vol.11, 29-43, 2010.

[18] K. Regmi, "A Review of Teaching Methods--Lecturing and Facilitation in Higher Education (HE): A Summary of the Published Evidence." Journal of Effective Teaching Vol.12, no. 3, 61-76, 2012.

[19] Westwood PS. "What teachers need to know about teaching methods." Aust Council for Ed Research; 2008.

[20] E. M. Ganyaupfu, "Teaching methods and students' academic performance." International Journal of Humanities and Social Science Invention Vol. 2, no. 9, 29-35, 2013.

[21] Covenant University" Covenant Tops in Research Endeavours among World Universities" http://covenantuniversity.edu.ng, 2017

[22] L. Billings, and J. Fitzgerald. "Dialogic Discussion and the Siddharth Seminar." American Educational Research Journal Vol. 10, no. 8, 212-223, 2002.

[23] H. Cooper, "Synthesis of research on homework." Educational leadership Vol. 47, no. 3, 85-91, 1989.

[24] R. Needlmen, "Homework: The Rules of the Game", 2001.

[25] Hartmann, Elizabeth. "Universal design for learning." Practice Perspectives: Highlighting Information on Deaf-Blindness no. 8, 1-4, 2011. 